\title{
CLINICAL EVALUATION OF GINGIVAL MARGIN STABILITY FOLLOWING CONVENTIONAL VERSUS MICROSURGICAL TECHNIQUES OF ESTHETIC CROWN LENGTHENING: A RANDOMIZED CONTROLLED CLINICAL TRIAL
}

\author{
Mohamed El-Shafie Hassan*, Manal Mohamed Hosny ${ }^{* *}$ and Weam Elbattawy***
}

\begin{abstract}
Aim: To assess the gingival margin stability following conventional versus microsurgical approach of esthetic crown lengthening in management of patients with anterior short clinical crowns.

Methodology: Twenty-four patients indicated for esthetic crown lengthening were selected and divided into either test or control groups where microsurgical approach or conventional technique were performed respectively. All patients were assessed at different intervals (baseline, 3 , and 6 months) for the outcomes: gingival margin (GM), Pink esthetic score (PES), soft tissue level (STL), mesial (MP) and distal papilla (DP) levels, postoperative swelling (POS), postoperative pain (POP) and patient satisfaction and were subjected to statistical analysis.

Results: there was a statistically significant reduction in the gingival margin level after 3 and 6 months in both groups with statistically significant more $\mathrm{mm}$ and percentage reduction within the control group. The microsurgical approach showed a statistically significant improvement in the PES at 3 and 6 months, while the conventional approach showed a statistically significant improvement only at 6 months with no statistically significant percentage gain between both groups at 3 and 6 months. Less pain was experienced with the test group through less intake of analgesics. Also, less swelling was observed in the test group at day 2 and day 5 with statistically significant difference with more patient satisfaction.
\end{abstract}

Conclusions: Both groups significantly improved all clinical outcomes after 6 months, but the microsurgical approach showed less postoperative pain, swelling and gained more patient satisfaction.

\footnotetext{
* Master candidate at periodontology department faculty of dentistry, Cairo University

** Professor and head of department and of Oral Medicine and Periodontology, Faculty of Dentistry, Cairo University

*** Ass. Prof. of Oral Medicine and Periodontology, Faculty of Dentistry, Cairo University
} 


\section{INTRODUCTION}

Periodontics is a branch of dentistry that searches for solutions in the construction of the facial esthetics, where the harmony between lips, teeth and gums is extremely important. Lips define the esthetic zone of what is considered a smile frame (Garber and Salama, 1996). According to the literature, some aspects should be observed to rate each patient's type of smile. The excessive gingival display when a patient smiles, known as gummy smile, along with short clinical crowns of the maxillary anterior teeth characterize esthetic problems (Kokich, Kiyak and Shapiro, 1999). Since there has been a growing demand by patients for esthetic solutions to their smile, therefore the current dentistry, which must be based on scientific evidence, has been searching for alternatives and new techniques on a regular and evolutionary basis (Storrer et al., 2014).

Different etiologies of gummy smile have been identified such as: excessive vertical bone growth, dentoalveolar extrusion, short upper lip, upper lip hyperactivity, altered passive eruption and the combination of some of these factors (Levine and McGuire, 1997). When gummy smile is caused by excessive gingival tissue partially covering the anatomical crown of the teeth, or in another expression caused by altered passive eruption, situation in which the gingival margin in the adult is located incisal to the cervical convexity of the crown and removed from the Cemento Enamel Junction (CEJ) of the tooth. This surgical technique is called esthetic crown lengthening and should be planned, without exposing the root surface, observing the amount of keratinized gingiva and the relationship between the cementoenamel junction, the gingival margin, and the alveolar bone crest (Seixas, CostaPinto and Araújo, 2011).

Removal of an adequate amount of bone is necessary to prevent coronal tissue rebound following crown lengthening surgery. Therefore, achievement of a stable gingival margin requires a surgical approach where the desired crown length is established through sufficient bone removal instead of soft tissue manipulation. As it relates to esthetic crown lengthening, osseous contouring must include additional considerations beyond the desired degree of crown extension. Because of its influence on the gingival margin outline and therefore esthetics, attention must be paid to details of the alveolar crest architecture; including interproximal peak levels, labial crest curvature, and zenith. Once the apicocoronal ostectomy is completed, an osteoplasty must be performed to restore the appropriate alveolar profile, contour, and scallop. This must include the re-creation of a gradual osseous crest taper, interproximal scalloping, and root prominences (Lee, 2017).

The techniques and tools for microsurgery were introduced for increased visual acuity and improved manual dexterity. Hence, microsurgical technique is a modification of the conventional surgery in which the gingival and bone tissues could be remodeled using the microsurgical kit of instruments (Kapadia et al., 2013). Therefore, microsurgical approaches in periodontology have been studied for various regenerative, root coverage and papilla reconstruction procedures and were reported to have the benefits of providing minimal tissue trauma and postoperative complications (Yadav et al., 2018).

However, the stability of the gingival margin after esthetic crown lengthening was suggested to be highly dependent on flap elevation, releasing not beyond the Mucogingival Junction (MGJ), and the post-surgical position of the gingival margin. In addition to the post-surgical healing time which is another key factor for the maturation and stability of the periodontal tissues prior to placing any definitive restoration (Domínguez et al., 2020).

Based on the available evidence in the literature, few studies have investigated the gingival marginal stability with esthetic crown lengthening procedures for managing patients with altered passive eruption. Also, no studies explored in detail the possible influence of using microsurgical approaches for such 
procedure and compare it to the conventional ones. Given the current knowledge gap, this randomized controlled clinical trial aimed to compare between microsurgical and conventional techniques in maintaining the gingival margin stability after esthetic crown lengthening in patients with altered passive eruption.

\section{MATERIALS AND METHODS}

\section{Study design:}

The present randomized, controlled, parallelgrouped trial included 24 patients (1 male and 23 females, aged 25 to 50 years) having short clinical crowns due to altered passive eruption and are candidates for esthetic crown lengthening with osteotomy. Four of the patients, did not attend their follow up appointments, so they were considered dropouts, thus a total of 20 patients ( 1 male\& 19 females) had completed their follow ups and were included in this study. Patients were randomly assigned into two groups; control group: where esthetic crown lengthening using conventional approach was performed and the test group, where esthetic crown lengthening was performed using microsurgical approach. Subjects were selected from the outpatient clinic, Department of Oral Medicine and Periodontology, Faculty of Dentistry, Cairo University between February 2019, and March 2020. Screening of patients was continued until the target sample was achieved. Identifying and recruiting potential subjects was achieved through patients' database. This clinical trial was registered in U.S. National Institutes of Health Clinical Trials Registry, ClinicalTrials.gov Identifier: ID: NCT03804281.

\section{Sample size determination:}

Based on a previous study by (Ribeiro et al., 2014) the minimal clinically important difference in gingival margin stability between the 2 groups as estimated by the expert was $(1 \mathrm{~mm})$. Using power
$80 \%$ and $5 \%$ significance level we needed to study 9 patients within each group to be sufficient to detect this difference. This number was to be increased by $30 \%$ to a sample size of 12 in each group to compensate for possible losses during the follow up period. Sample size calculation was achieved using PS program.

\section{Randomization:}

The participants included in this trial were randomly assigned to receive esthetic crown lengthening using either conventional technique (control group) or esthetic crown lengthening using microsurgical approach (test group) using a distance randomization procedure with a 1:1 allocation ratio. A computer-generated randomization* list was executed by a faculty member who was not involved in the patients' recruitment and the list was sent to the main supervisor for the purpose of concealment.

\section{Blinding:}

The current investigation was a double-blinded clinical trial. Blinding included patients, the outcome assessor, and the statistician. It was impossible for the operator who performed the surgical procedure to be blinded as the interventions were completely different.

\section{Clinical outcomes:}

Mid-buccal gingival margin level: The UNC 15 probe was used to measure the distance from the CEJ to the gingival margin at the mid-buccal surface of each tooth involved in the surgical procedure at baseline then at 3 and 6 months post-surgically (Ribeiro et al., 2014).

Pink Esthetic Score (PES): was based on seven variables: mesial papilla, distal papilla, soft-tissue level, soft tissue contour, alveolar process deficiency, soft-tissue color and texture. Each variable was assessed with a 2-1-0 score, with 2 being the best and 0 being the poorest score (Fürhauser et al., 2005).

\footnotetext{
* Research Randomizer computer software (Version 4.0). Retrieved on August 16, 2015, from http://www.randomizer.org/
} 
Patient reported quality of life related outcomes:

Post-operative pain (POP): It was evaluated indirectly based on the mean consumption (in $\mathrm{mg}$ ) of analgesics (ibuprofen) ${ }^{*}$ after the surgical procedures (Wessel and Tatakis, 2008).

Post-operative swelling: It was reported by the patients through the first week (7 days) postsurgically based on the Verbal Rating Scale (VRS) values (absent, slight, moderate and severe) (García et al., 2008).

Post-Surgical Patient Satisfaction: A 3-item questionnaire was given to the patients to be answered using a 7-point answer scale for assessing their satisfaction with the whole procedure and the results of the procedure performed (Kiyak $\boldsymbol{e t}$ al., 1984).

\section{Preoperative phase:}

Initial examination, including full mouth probing and radiographic examination was performed for the selected patients. Patient motivation and education for proper oral hygiene instructions included twicedaily tooth brushing with soft toothbrush using modified bass brushing technique and once daily interdental cleaning with interdental brushes for wide interproximal embrasure spaces. Full mouth supra and subgingival debridement was performed using ultrasonic device with supragingival scaling inserts. $0.12 \%$ chlorhexidine HCL mouth rinse twice daily was prescribed for 2 weeks.

\section{Surgical phase}

After a period of 4-6 weeks from initial therapy, patients fulfilling the inclusion criteria were recalled and scheduled for surgery. Each patient was allocated into one of the two groups after completing local anesthesia and confirming that the defect fulfilled the inclusion criteria intra-operatively according to the randomization list that was concealed. The surgical procedure was initiated with demarcation of CEJ position on the mid-buccal aspect of the teeth. By measuring the centrals width (on the contact level), ideal tooth length was calculated, and zenith points were marked using a tissue pen. Papilla levels were evaluated, if it needs to be shortened, it was included in the cutting design. if not, the cutting line was thinned from the zenith point to the papilla tip. Clinical parameters were measured and recorded on the day of surgery (baseline) then 3 and 6 months postoperatively in both groups. Supragingival scaling for oral hygiene maintenance was repeated at the recall sessions and the patients were reinforced in oral hygiene instructions each month.

For the control group (Figure 1), an internal bevel incision using $15 \mathrm{c}$ blade, following CEJ anatomy, was made at each tooth, preserving interdental papillae if needed. This was followed by an intra-sulcular incision, removal of the strip of outlined marginal gingiva and elevation of a mucoperiosteal flap to the level of the alveolar bone crest showing 2-3 $\mathrm{mm}$ of bone using normal mucoperiosteal elevator. The CEJ-alveolar bone crest $(\mathrm{ABC})$ distance was measured on the midbuccal, and then ostectomy and osteoplasty using end-cutting bur and round bur, aiming to attain a $2 \mathrm{~mm}$ CEJ-ABC distance. Finally, the flap was repositioned and vertical internal mattress suture 4/0 vicryl ${ }^{* *}$ was done to keep the papillae in place using normal needle holder (Palomo and Kopczyk, 1978; Deas et al., 2004; Lipska et al., 2015).

For the intervention group (Figure 2), Surgery was done the same as in the conventional approach but with the use of $4 \mathrm{x}$ magnification loupe, micro blades, and micro-sutures (6/0) within the microsurgical instrument kit (Shanelec, 2003; Yadav et al., 2018).

\footnotetext{
* Brufen, 400 mg tablets, KAHIRA PHARM. CO. EGYPT.

** Demophorius Healthcare, Cyprus
} 


\section{Statistical analysis}

Numerical data were described as mean and standard deviation as well as median and $25^{\text {th }}$, $75^{\text {th }}$ percentiles for non-normally distributed data. Numerical data were explored for normality using Kolmogorov-Smirnov test and Shapiro-Wilk test. In the case of normally distributed numerical variables (age, pain, difference in gingival margin, difference in PES, patient satisfaction), a comparison between both groups was done using independent t-test.
For inter-group comparisons of non-normally distributed and ordinal variables, Mann Whiney $\mathrm{U}$ test was utilized. Intragroup comparisons were done using Wilcoxon Signed Ranks Test. Nominal data were reported as frequency and percentage and were analyzed using Fisher's exact test. All tests were two-tailed and P-value less than 0.05 was be considered statistically significant. Data were analyzed using SPSS advanced statistics (Statistical Package for Social Sciences version 26, BM Inc., Chicago, IL).

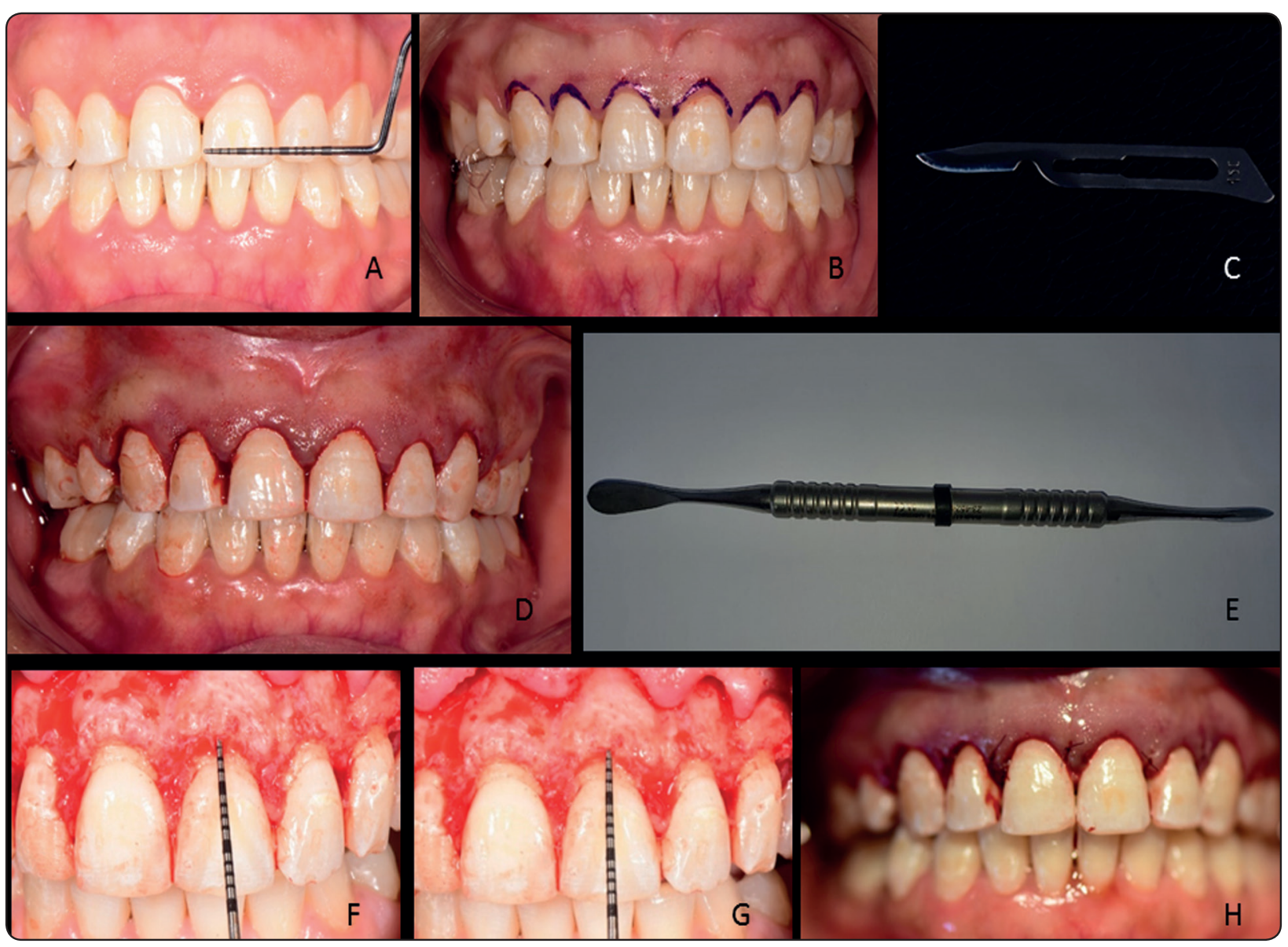

Fig. (1) Control group clinical photographs. (A) measuring tooth width and ratios. (B) pen guiding markings. (C) $15 \mathrm{c}$ blade. (D) clinical photograph after the internal bevel incision. (E) mucoperiosteal elevator. (F) flap elevation and bone before ostectomy. (G) ostectomy with $2 \mathrm{~mm}$ CEJ-ABC distance. (I) flap repositioned with simple interrupted suture. 


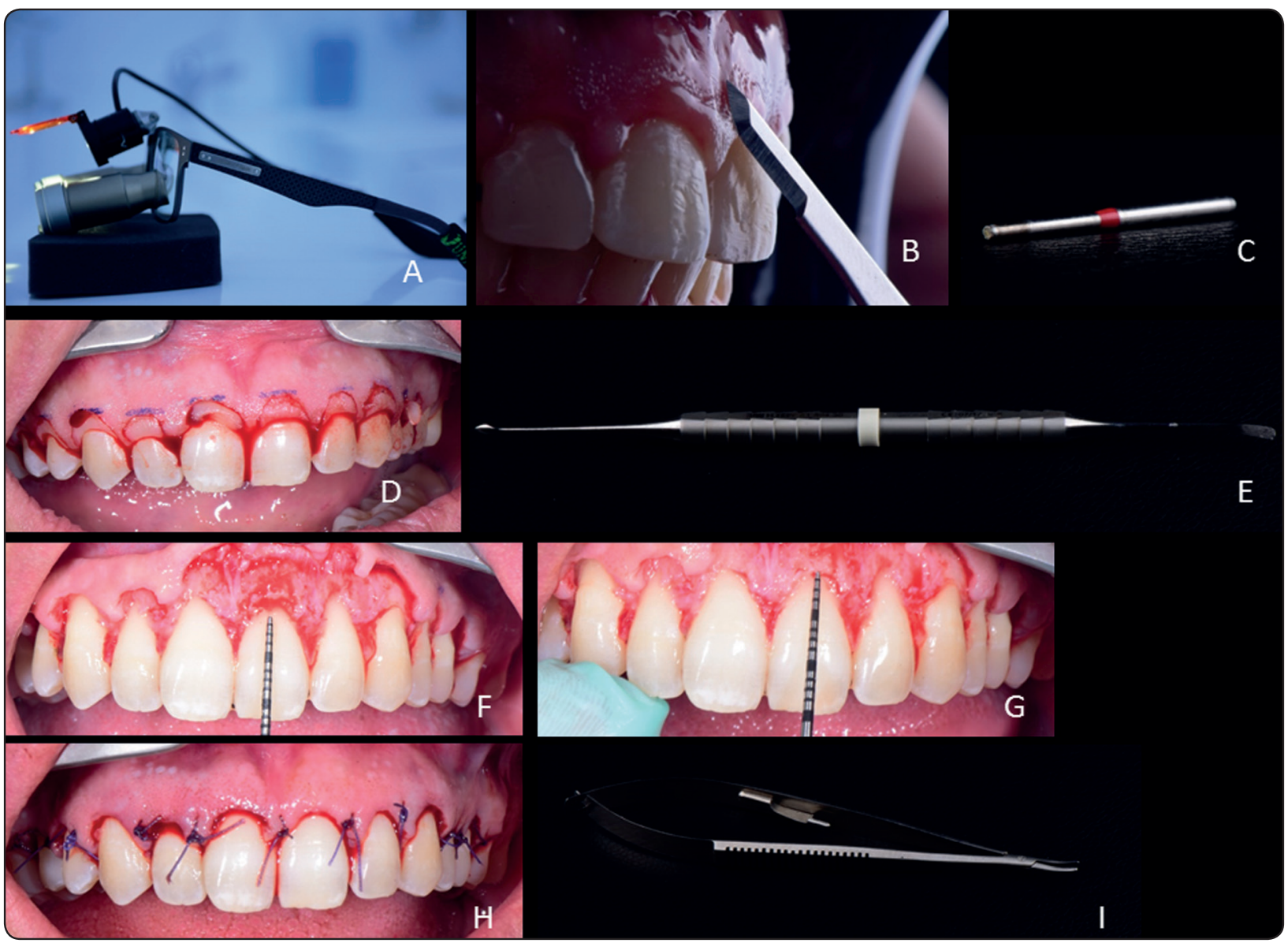

Fig. (2) Test group clinical photographs. (A) prismatic 4x magnification loupe with led light. (B) micro blade size in comparison to papilla. (C) end-cutting bur used in both groups. (D) internal bevel incision with micro blade. (E) micro mucoperiosteal elevator. (F) flap elevation and bone before ostectomy. (G) ostectomy with $2 \mathrm{~mm}$ CEJ-ABC distance. (H) flap repositioned with simple interrupted suture. (I) Castroviejo needle holder.

\section{RESULTS}

\section{Demographic data}

The study's population in this randomized, parallel-grouped clinical trial included a total of 24 patients (1 male and 23 females) with a mean $( \pm$ SD) age of $(29.20 \pm 3.26)$ and $(26.50 \pm 2.72)$ years of the test and control group, respectively. The patients were randomly assigned into two equal groups: a control group receiving esthetic crown lengthening using conventional approach and a test group: receiving esthetic crown lengthening using microsurgical approach. The study was completed with 20 patients ( 1 male\& 19 females), 10 patients allocated for each group. There was no statistical significance between the two groups regarding the age and gender $(P \geq 0.05)$

\section{Changes in Mid-buccal gingival margin level (GM)}

Changes in the mean GM $( \pm \mathrm{SD})$ in mm between the two groups throughout the study period are presented in (table 1). There was no statistically significant difference $(P \geq 0.05)$ in the mean $G M$ in mm between the two treatment modalities at baseline, however at 3 and 6 months there was statistically significant difference $(\mathrm{P}<0.05)$. Additionally, there was statistical significance difference $(\mathrm{P}<0.05)$ in both $\mathrm{mm}$ and percentage gingival marginal reduction between the two treatment modalities after 3 months and 6 months. 
TABLE (1): The mean $( \pm \mathrm{SD})$ and percentage of the mean difference [95\% CI] for comparison between outcomes measurements in the two groups throughout the study.

\begin{tabular}{|c|c|c|c|c|}
\hline & $\begin{array}{c}\text { Test } \\
\text { Mean } \pm \text { SD }\end{array}$ & Control Mean \pm SD & Mean difference $[95 \% \mathrm{CI}]$ & $\begin{array}{l}\text { Intergroup } \\
\text { p-value }\end{array}$ \\
\hline \multicolumn{5}{|c|}{ 1- Mid-buccal gingival margin level (GM) } \\
\hline Baseline (mm) & $3.11 \pm 0.53$ & $3.02 \pm 0.28$ & $0.09[-0.31,0.49]$ & 0.878 \\
\hline 3 months (mm) & $1.77 \pm 0.35$ & $1.29 \pm 0.33$ & $0.48[0.16,0.80]$ & $0.019 *$ \\
\hline 6 months (mm) & $1.80 \pm 0.37$ & $1.33 \pm 0.29$ & $0.47[0.16,0.78]$ & $0.005^{*}$ \\
\hline $\begin{array}{l}\text { Gingival margin reduction at } 3 \\
\text { months (mm) }\end{array}$ & $1.34 \pm 0.35$ & $1.73 \pm 0.36$ & $-0.39[-0.72,-0.06]$ & $0.025^{*}$ \\
\hline $\begin{array}{l}\text { Gingival margin reduction at } 3 \\
\text { months } \%\end{array}$ & $42.92 \pm 7.58$ & $57.31 \pm 11.38$ & $-14.39[-23.47,-5.30]$ & $0.004 *$ \\
\hline $\begin{array}{l}\text { Gingival margin reduction at } 6 \\
\text { months }(\mathrm{mm})\end{array}$ & $1.31 \pm 0.36$ & $1.69 \pm 0.37$ & $-0.38[-0.72,-0.04]$ & $0.032 *$ \\
\hline $\begin{array}{l}\text { Gingival margin reduction at } 6 \\
\text { months }(\%)\end{array}$ & $41.99 \pm 8.19$ & $55.79 \pm 10.26$ & $-13.80[-22.55,-5.05]$ & $0.004 *$ \\
\hline \multicolumn{5}{|l|}{ 2- $\quad$ Pink Esthetic Score (PES) } \\
\hline Baseline & $12.16 \pm 1.13$ & $12.25 \pm 0.058$ & $-0.09[-0.93,0.75]$ & 0.786 \\
\hline 3 months & $13.17 \pm 0.65$ & $12.67 \pm 0.67$ & $0.50[-0.12,1.12]$ & 0.099 \\
\hline 6 months & $13.85 \pm 0.21$ & $13.15 \pm 0.63$ & $0.70[0.24,1.16]$ & $0.001 *$ \\
\hline PES gain at 3 months & $1.01 \pm 0.56$ & $0.42 \pm 0.70$ & $0.59[-0.003,1.18]$ & 0.051 \\
\hline PES gain at 3 months \% & $8.76 \pm 5.68$ & $3.55 \pm 5.86$ & $5.21[-0.21,10.64]$ & 0.059 \\
\hline PES gain at 6 months & $1.69 \pm 0.96$ & $0.90 \pm 0.96$ & $0.79[-0.11,1.69]$ & 0.082 \\
\hline PES gain at 6 months $(\%)$ & $14.74 \pm 10.27$ & $7.62 \pm 8.25$ & $7.12[-1.63,15.87]$ & 0.105 \\
\hline 3- $\quad \underline{\text { Pain (mg) }}$ & $760 \pm 478.89$ & $2040 \pm 1057.46$ & $-1280[-2076.00,-484.00]$ & $0.004 *$ \\
\hline 4- $\quad \underline{\text { VAS }}$ & $6.80 \pm 0.42$ & $5.60 \pm 0.97$ & $1.20[0.48,1.92]$ & $0.004 *$ \\
\hline \multicolumn{5}{|l|}{ 5- $\quad$ Post-operative swelling } \\
\hline Baseline & $0.30 \pm 0.48$ & $0.50 \pm 0.53$ & $-0.20[-0.68,0.28]$ & 0.374 \\
\hline Day 1 & $1.00 \pm 0.81$ & $1.90 \pm 1.10$ & $-0.90[-1.81,0.01]$ & 0.065 \\
\hline Day 2 & $0.90 \pm 0.88$ & $2.60 \pm 0.52$ & $-1.70[-2.38,-1.03]$ & $0.001 *$ \\
\hline Day 3 & $1.00 \pm 1.05$ & $1.70 \pm 1.42$ & $-0.70[-1.88,0.48]$ & 0.165 \\
\hline Day 4 & $0.20 \pm 0.63$ & $0.50 \pm 0.53$ & $-0.30[-0.85,0.25]$ & 0.099 \\
\hline Day 5 & $0.00 \pm 0.00$ & $0.50 \pm 0.53$ & $-0.50[-0.85,-0.15]$ & $0.012 *$ \\
\hline Day 6 & $0.00 \pm 0.00$ & $0.00 \pm 0.00$ & 0.00 & 1.00 \\
\hline Day 7 & $0.00 \pm 0.00$ & $0.00 \pm 0.00$ & 0.00 & 1.00 \\
\hline
\end{tabular}

*Statistically significant at $P<0.05 . \quad * C I$ : confidence interval 


\section{Changes in Pink Esthetic Score (PES)}

Changes in the mean PES $( \pm \mathrm{SD})$ between the two group throughout the study period are shown in (table 1). There was no statistically significant difference $(\mathrm{P} \geq 0.05)$ in the mean PES between the two treatment modalities at baseline and 3 months, but at 6 months there was statistically significant difference $(\mathrm{P}<0.05)$. Additionally, there was no statistical significance difference $(\mathrm{P} \geq 0.05)$ in both mean and percentage PES increase between the two treatment modalities after 3 and 6 months.

\section{Changes in Post-Operative Pain (POP)}

In test group, the mean $( \pm \mathrm{SD})$ of consumption of the analgesic in mg was $(760 \pm 478.89)$ while in the control group, it was $(2040 \pm 1057.46)$ with mean difference of -1280 [95 \% CI] [-2076.00, -484.00]. There was a statistically significant difference in favor of the test group where patients consumed less analgesics $(p=0.004)$ (table 1).

\section{Changes in Post-operative swelling (VRS)}

Post-operative swelling values measured using VRS in both groups throughout the post-surgical 7 days are presented in (table 1). There was only statistically significant difference between the two groups in favor of the microsurgical intervention at day $2(\mathrm{p}=0.001)$ and at day $5(\mathrm{p}=0.012)$.

\section{Changes in Patient satisfaction (VAS)}

Patient satisfaction was recorded by VAS and the mean $( \pm \mathrm{SD})$ was $(6.80 \pm 0.42)$ and $(5.60 \pm 0.97)$ in test and control groups respectively, with the mean difference of 1.20 [95\% CI] [0.48, 1.92]. There was a higher patient satisfaction in the test group compared to the control one with statistically significant difference $(\mathrm{p}=0.004)$ (table 1).

\section{DISCUSSION}

Altered passive eruption (APE) is one of the common factors that contribute to development of gummy smile. APE described as a situation in which the gingival margin in the adult is located incisal to the cervical convexity of the crown and removed from the CEJ of the tooth (Robbins, 1999). This condition is often called 'delayed passive eruption' in the literature and results from the failure to end the passive eruption process. The incidence of APE in a cohort of 1025 patients with a mean age of $24.2 \pm 6.2$ years was reported to be $12.1 \%$ (Volchansky and Cleaton-Jones, 1974). More recently the incidence in healthy volunteers was reported to be $29.55 \%$ compared to $42.1 \%$ in orthodontically treated patients (Nart et al., 2014).

In the test group a microsurgical approach was adopted in performing the esthetic crown lengthening procedure so that proper teeth/gingival display and improved patients' smiles can be obtained along with less tissue trauma and more soft tissue stability. Microsurgery is based upon magnification and enhanced illumination of the surgical field. Magnification of can be obtained using loupes or microscope during the surgical procedure to enhance visibility. Magnification with enhanced illumination minimize surgical invasiveness, enables more precise incisions and intimate suture adaptation of wound edges (Agarwal et al., 2016). This approach may lead to enhanced soft tissue stability, less postoperative discomfort, better predictability, and esthetic outcome (Kang et al., 2015). Currently, there is increasing interest in incorporation of microsurgical disciplines in periodontal and implant surgery (Yadav et al., 2018). Periodontal microsurgery has been shown to enhance clinical outcomes and reduce patients' morbidity following regenerative therapy (Cortellini and Tonetti, 2009; Fickl et al., 2009). Plastic periodontal surgery often employed microsurgery in root coverage procedures with reported increase in percentage of root coverage, increased soft tissue thickness and stability of gingival tissues compared to conventional techniques (Nizam et al., 2015; Moro et al., 2020).

All procedures in the test group of the current study were done while the operator was using 
magnification loupes of $\times 4$. A basic set of microsurgical instruments was used to complement magnification and illumination. Micro-blades were used instead of $15 \mathrm{c}$ blades where microscalpel incisions result in less inflammation and increased tensile strength compared with electrocautery and higher tensile strength compared to the $15 \mathrm{c}$ blade (Pearce et al., 2014). The advantage of these knives is their small size and extreme sharpness. This enables clean, non-ragged incisions to achieve wound healing by primary intention (Yadav $\boldsymbol{e t}$ al., 2018).

The stability of the soft tissue margin following a crown lengthening procedure is essential to maintain the esthetic outcomes of the surgical procedures. Thus, it was considered the primary outcome of the present study. Several studies reported coronal displacement of the gingival margin (Brägger et al., 1992; Arora et al., 2013; Deas et al., 2014). A rebound of the gingival margin (GM) can lead to an aesthetics compromise as well as an alteration of the periodontal health (Mele et al., 2018). Several studies revealed rebound of the gingival margin after crown lengthening procedure. In the present study the position of the gingival margin did not exhibit significant difference between 3 and 6 months with no rebound of gingival margin position compared to baseline. Similar findings were reported by (Lanning et al., 2003; Cairo et al., 2012). Of the factors that contribute to coronal shift of the gingival margin after crown lengthening the position of the flap margin after surgery. Suturing of the flap margin at $3 \mathrm{~mm}$ or more from the alveolar crest contribute to stability of gingival margin as reported by (Deas $\boldsymbol{e t}$ al., 2004; Arora et al., 2013). In addition, there is reduced tendency for rebound of gingival margin with establishment of biologic width of $2 \mathrm{~mm}$ or more with the esthetic crown lengthening procedure (Camargo et al., 2007; Rossi et al., 2009). The result in the present study generally agrees with these studies as a distance of $2 \mathrm{~mm}$ between the alveolar crest and CEJ was provided for biologic width and the flap margin was sutured coronal to the CEJ.

\section{CONCLUSION}

Both groups showed a statistically significant reduction in the gingival margin level at 3 and 6 months postoperatively compared to baseline values with statistically significant more $\mathrm{mm}$ and percentage reduction within the control group at 3 and at 6 months. The microsurgical approach showed a statistically significant improvement in the PES at 3 and 6 months postoperatively, while the conventional approach showed a statistically significant improvement only at 6 months but with no statistically significant percentage gain between both groups at 3 and 6 months. Less postoperative pain was experienced with the microsurgical test group through less intake of analgesics with a statistically significant difference when compared to the control group. Less swelling was observed within the microsurgical test group only at day 2 and day 5 with statistically significant difference. More patient satisfaction was expressed from patients within the test group over those in the control group. Hence, the microsurgical approach in esthetic crown surgery gives more precision to the operator and a better patient experience.

\section{REFERENCES}

- $\quad$ Agarwal, S. K., Jhingran, R., Bains, V. K., Srivastava, R., Madan, R. and Rizvi, I. (2016) 'Patient-centered evaluation of microsurgical management of gingival recession using coronally advanced flap with platelet-rich fibrin or amnion membrane: A comparative analysis', Eur J Dent, 10(1), pp. $121-133$

- $\quad$ Arora, R., Narula, S. C., Sharma, R. K. and Tewari, S. (2013) 'Evaluation of supracrestal gingival tissue after surgical crown lengthening: a 6-month clinical study', J Periodontol, 84(7), pp. 934-40.

- $\quad$ Brägger, U., Lauchenauer, D. and Lang, N. P. (1992) 'Surgical lengthening of the clinical crown', J Clin Periodontol, 19(1), pp. 58-63.

- Cairo, F., Graziani, F., Franchi, L., Defraia, E. and Pini Prato, G. P. (2012) 'Periodontal plastic surgery to improve aesthetics in patients with altered passive eruption/ gummy smile: a case series study', International journal of dentistry, 2012. 
- Camargo, P. M., Melnick, P. R. and Camargo, L. M. (2007) 'Clinical crown lengthening in the esthetic zone', J Calif Dent Assoc, 35(7), pp. 487-98.

- Cortellini, P. and Tonetti, M. S. (2009) 'Improved wound stability with a modified minimally invasive surgical technique in the regenerative treatment of isolated interdental intrabony defects', J Clin Periodontol, 36(2), pp. $157-63$.

- Deas, D. E., Mackey, S. A., Sagun Jr, R. S., Hancock, R. H., Gruwell, S. F. and Campbell, C. M. (2014) 'Crown lengthening in the maxillary anterior region: a 6-month prospective clinical study', International Journal of Periodontics \& Restorative Dentistry, 34(3).

- Deas, D. E., Moritz, A. J., McDonnell, H. T., Powell, C. A. and Mealey, B. L. (2004) 'Osseous surgery for crown lengthening: A 6-month clinical study', Journal of periodontology, 75(9), pp. 1288-1294.

- $\quad$ Domínguez, E., Pascual-La Rocca, A., Valles, C., Carrió, N., Montagut, L., Alemany, A. S. and Nart, J. (2020a) 'Stability of the gingival margin after an aesthetic crown lengthening procedure in the anterior region by means of a replaced flap and buccal osseous surgery: a prospective study', Clinical Oral Investigations, pp. 1-8.

- Fickl, S., Thalmair, T., Kebschull, M., Böhm, S. and Wachtel, H. (2009) 'Microsurgical access flap in conjunction with enamel matrix derivative for the treatment of intra-bony defects: a controlled clinical trial', J Clin Periodontol, 36(9), pp. 784-90.

- $\quad$ Fürhauser, R., Florescu, D., Benesch, T., Haas, R., Mailath, G. and Watzek, G. (2005) 'Evaluation of soft tissue around single-tooth implant crowns: the pink esthetic score', Clin Oral Implants Res, 16(6), pp. 639-44.

- Garber, D. A. and Salama, M. A. (1996) 'The aesthetic smile: diagnosis and treatment', Periodontol 2000, 11, pp. 18-28.

- García, B., Larrazabal, C. and Peñarrocha, M. (2008) 'Pain and swelling in periapical surgery. A literature update', Med Oral Patol Oral Cir Bucal, 13(11), pp. E726-9.

- $\quad$ Kang, J., Meng, S., Li, C., Luo, Z., Guo, S. and Wu, Y. (2015) 'Microsurgery for root coverage: A systematic review', Pak J Med Sci, 31(5), pp. 1263-8.

- $\quad$ Kokich, V. O., Kiyak, H. A. and Shapiro, P. A. (1999) 'Comparing the perception of dentists and lay people to altered dental esthetics', J Esthet Dent, 11(6), pp. 311-24.

- $\quad$ Kapadia, J. A., Bhedasgoankar, S. Y. and Bhandari, S. D. (2013) 'Periodontal microsurgery: A case report', Journal of Indian Society of Periodontology, 17(6), pp. 790.

- $\quad$ Kiyak, H. A., Hohl, T., West, R. A. and McNeill, R. W. (1984) 'Psychologic changes in orthognathic surgery patients: a 24-month follow up', J Oral Maxillofac Surg, 42(8), pp. 506-12.

- Lanning, S. K., Waldrop, T. C., Gunsolley, J. C. and Maynard, J. G. (2003) 'Surgical crown lengthening: evaluation of the biological width', J Periodontol, 74(4), pp. 468-74.

- Lee, E.A. (2017) 'Esthetic crown lengthening: contemporary guidelines for achieving ideal gingival architecture and stability', Current Oral Health Reports, 4(2), pp. 105-111.

- $\quad$ Levine, R. A. and McGuire, M. (1997) 'The diagnosis and treatment of the gummy smile', Compend Contin Educ Dent, 18(8), pp. 757-62, 764; quiz 766.

- Lindhe, J., Lang, N. P. and Karring, T. (2008) Clinical periodontology and implant dentistry. Blackwell munksgaard Oxford.

- Lipska, W., Lipski, M., Lisiewicz, M., Gala, A., Gronkiewicz, K., Darczuk, D. and Chomyszyn-Gajewska, M. (2015) 'Clinical crown lengthening - a case report', Folia Med Cracov, 55(3), pp. 25-35.

- Mele, M., Felice, P., Sharma, P., Mazzotti, C., Bellone, P. and Zucchelli, G. (2018) 'Esthetic treatment of altered passive eruption', Periodontol 2000, 77(1), pp. 65-83.

- Moro, M., Souto, M. L., Rovai, E., Cesar Neto, J., Holzhausen, M. and Pannuti, C. (2020) 'Effect of magnification on root coverage surgery', Brazilian Journal of Oral Sciences, 19, pp. e201669.

- $\quad$ Nart, J., Carrió, N., Valles, C., Solís-Moreno, C., Nart, M., Reñé, R., Esquinas, C. and Puigdollers, A. (2014) 'Prevalence of altered passive eruption in orthodontically treated and untreated patients', Journal of periodontology, 85(11),pp. e348-e353.

- $\quad$ Nizam, N., Bengisu, O. and Sönmez, Ş. (2015) 'Microand macrosurgical techniques in the coverage of gingival recession using connective tissue graft: 2 years follow-up', J Esthet Restor Dent, 27(2), pp. 71-83.

- Palomo, F. and Kopczyk, R. A. (1978) 'Rationale and methods for crown lengthening', J Am Dent Assoc, 96(2), pp. 257-60.

- $\quad$ Pearce, E. C., Hall, J. E., Boyd, K. L., Rousseau, B. and Ries, W. R. (2014) 'The ophthalmology microscalpel versus standard scalpels and wound healing in a rat model', Otolaryngol Head Neck Surg, 151(3), pp. 424-30. 
- $\quad$ Ribeiro, F. V., Hirata, D. Y., Reis, A. F., Santos, V. R., Miranda, T. S., Faveri, M. and Duarte, P. M. (2014) 'Openflap versus flapless esthetic crown lengthening: 12-month clinical outcomes of a randomized controlled clinical trial', Journal of periodontology, 85(4), pp. 536-544.

- $\quad$ Robbins, J.W.(1999) 'Differential diagnosis and treatment of excess gingival display', Practical periodontics and aesthetic dentistry: PPAD, 11(2), pp. 265-72; quiz 273.

- $\quad$ Rossi, R., Pilloni, A. and Morales, R. S. (2009) 'Qualitative assessment of connective tissue graft with epithelial component. A microsurgical periodontal plastic surgical technique for soft tissue esthetics', Eur J Esthet Dent, 4(2), pp. 118-28.

- Seixas, M. R., Costa-Pinto, R. A. and Araújo, T. M. d. (2011) 'Checklist of aesthetic features to consider in diagnosing and treating excessive gingival display (gummy smile)', Dental Press Journal of Orthodontics, 16(2), pp. 131-157.
- $\quad$ Shanelec, D. A. (2003) 'Periodontal microsurgery', J Esthet Restor Dent, 15(7), pp. 402-7; discussion 408.

- $\quad$ Storrer, C. L. M., Valverde, F. K. B., Santos, F. R. and Deliberador, T. M. (2014) 'Treatment of gummy smile: Gingival recontouring with the containment of the elevator muscle of the upper lip and wing of nose. A surgery innovation technique', Journal of Indian Society of Periodontology, 18(5), pp. 656.

- Volchansky, A. and Cleaton-Jones, P. (1974) 'Delayed passive eruption. A predisposing factor to Vincent's infection', J Dent Assoc S Afr, 29, pp. 291-294.

- Wessel, J. R. and Tatakis, D. N. (2008) 'Patient outcomes following subepithelial connective tissue graft and free gingival graft procedures', J Periodontol, 79(3), pp. 425-30.

- Yadav, V. S., Salaria, S. K., Bhatia, A. and Yadav, R. (2018) 'Periodontal microsurgery: Reaching new heights of precision', Journal of Indian Society of Periodontology, 22(1), pp. 5. 